\title{
A EDUCAÇÃO NUM RITMO DIFERENTE DE APRENDIZAGEM E INTERAÇÃO - O PAPEL DO DOCENTE COMO FACILITADOR NA EDUCAÇÃO À DISTÂNCIA EM UM CURSO SUPERIOR DE TECNOLOGIA
}

\author{
EDUCATION IN A DIFFERENT RATE OF LEARNING AND INTERACTION - THE ROLE \\ OF THE TEACHER AS A FACILITATOR IN DISTANCE EDUCATION IN A HIGHER \\ TECHNOLOGY COURSE
}

\author{
Marcelo Eloy Fernandes \\ Universidade Cruzeiro do Sul, marceloeloyfernandes@gmail.com \\ Juliano Schimiguel \\ Universidade Cruzeiro do Sul, schimiguel@gmail.com \\ Marcio André Ferreira Pereira \\ Universidade Presbiteriana Mackenzie, marcio@pereira.eti.br \\ Ingrid Hötte Ambrogi \\ Universidade Presbiteriana Mackenzie, ihambrogi@gmail.com \\ Marcelo Tsuguio Okano \\ Centro Paula Souza, marcelo.okano@cps.sp.gov.br
}

\section{Resumo}

Este artigo trata da educação a distância, da mediação e o papel do professor neste tipo de curso. A educação a distância requer um ritmo diferente da educação presencial, e alunos e educadores deste novo processo, aprendem a interagir por diferentes meios, em diferentes condições. Neste contexto, o objetivo deste artigo é o de descrever o papel do professor na educação a distância, levantando como problema, qual o papel do docente como facilitador no processo de ensino e aprendizagem no curso superior tecnológico a distância em uma Universidade localizada na região da grande São Paulo. Para desenvolvimento deste artigo é apresentada uma pesquisa de campo com cinquenta professores que ministram aulas em um curso superior de tecnologia a distância da instituição de ensino estudada, além da fundamentação teórica que suporta o desenvolvimento deste trabalho. A conclusão e os resultados obtidos são de que o papel do professor no curso à distância é o de apoiar o aluno a aprender, criar condições para que ele adquira informações de forma autônoma, e organizar estratégias para que este conheça e construa seu próprio conhecimento, ou seja, o docente no curso superior tecnológico à distância contribui tanto para que o discente amplie seus conhecimentos teóricos, quanto sua bagagem para a formação do profissional.

Palavras-chave: educação; tecnologia de informação; ensino a distância, docente 


\section{Abstract}

This article is about Distance Learning, mediation and the teacher's role in this kind of course. Distance learning requires a different rhythm from classroom learning, and educators of this new process learn to interact in different ways and conditions. The purpose of this article is describing the teacher's role in distance learning, and rises as a problem, the role of the teacher as facilitator in the process of teaching and learning in higher school of distance technology. For its development is presented one search field; with fifty teachers, who teaches in a higher school of distance technology. The conclusion and the results are the teacher's role in distance learning course is to help students learn to create the conditions for getting information to them, and organizing strategies to the student meet and build his own knowledge, that's mean, the teacher or facilitator in the distance technology higher school helps the students broaden their knowledge.

Keywords: Education; Information Technology; Distance Learning.

\section{Introdução}

Este artigo trata da educação a distância e da mediação entre professor e aluno.

Como se sabe, num programa educacional o aluno é o foco, e uma das bases de garantia de qualidade num curso superior de tecnologia a distância, se encontra na interação entre professores e alunos, cujo relacionamento tornou-se ainda mais estreito e simples, em virtude dos avanços das tecnologias da informação e da comunicação.

Todavia, um ensino a distância demanda recursos humanos e educacionais, assim, como recursos tecnológicos e avaliações que permitam ao aluno atingir resultados ao longo do processo ensino-aprendizagem.

A educação a distância requer um ritmo diferente da educação presencial, alunos e educadores deste novo processo, aprendem a interagir por diferentes meios, em diferentes condições, favorecendo assim a aprendizagem e o conhecimento no ambiente virtual.

Neste sentido, o objeto desta pesquisa se encontra na tecnologia de informação aplicada ao ensino a distância, e o objetivo geral do estudo está em descrever o papel do professor na educação a distância em um curso superior de tecnologia em uma Universidade localizada na grande São Paulo. Assim, o artigo levanta como problema o seguinte questionamento: Qual o papel do docente no processo de ensino e aprendizagem no curso superior tecnológico a distância?

A hipótese levantada inicialmente para o artigo proposto, é a de que o docente no curso superior tecnológico a distância, contribui para que o discente amplie seus conhecimentos e habilidades profissionais, e para tal, suas atribuições estão em mediar e interagir com o acadêmico para sanar suas dúvidas ou prover-lhe suporte, pois, este 
como facilitador deste processo, deve incentivar a aprendizagem do aluno, uma vez que esse professor se mostra como um elo entre o aprendiz e a aprendizagem, destacando o diálogo, a troca de experiências, o debate e a proposição de situações-problema na formação desse futuro profissional e discutida de forma ampla no decorrer deste estudo.

A fundamentação do método deste artigo será dividida em duas etapas distintas das quais fundamentaram o desenvolvimento deste trabalho. A primeira etapa será amparada pela revisão bibliográfica da temática relacionada ao assunto "ensino a distância" e "tecnologia da informação". Nessa técnica de pesquisa, o pesquisador busca referência para a pesquisa publicadas em livros, revistas acadêmicas, periódicos, teses, dissertações, teses, entre outros, caracterizado pela coleta de dados e informações que darão robustez a pesquisa de fato, conforme visto nos itens que acompanham este artigo.

Para dar credibilidade ao referencial teórico aqui proposto foram pesquisadas as seguintes bases de dados e motores de busca, conforme segue: EBSCO, Emerald, PROQUEST, SCOPUS, no período de janeiro a abril de 2019, utilizando-se as palavraschaves: "ensino a distância, tecnologia da informação e docente", bem como as suas diversas variações para a seleção proposta.

Como parte integrante da revisão bibliográfica, buscou-se discutir os aspectos que normatizam o ensino a distância no Brasil, com o intuito de identificar nos aspectos legais o amparo da lei, bem como situar o leitor no cenário ao qual encontram se envolvidos tanto ensino a distância quanto as novas tecnologias da informação. Já em segundo momento e dialogando com os dados: levantados, estratificados e discutidos da pesquisa, serão analisados os instrumentos, atividades e as características do professor no processo de mediação no EAD para o estudo particularizado.

\section{Educação}

Os primórdios da educação brasileira são marcados pela chegada dos padres jesuítas. Assim, de acordo com Niskier (2011, p. 47) "durante o longo período do regime colonial em que viveu o nosso país, rudimentaríssimo era o ensino primário, limitado ao mínimo em atrasadíssimas escolas mantidas pelos padres jesuítas aqui instalados desde 1549, em missão de catequese dos silvícolas".

Desde o seu início, o sistema educacional era organizado e estruturado de maneira que preenchesse as necessidades da vida econômica da época, ou seja, os portugueses visavam tão somente à riqueza e a fortuna, eles exploravam e usufruíam a riqueza do país. 
Mas, a chegada de D. João VI no início do século XIX, fez com que algumas mudanças acontecessem. A partir de então, segundo Freitag (1986) surgiu a necessidade da formação de novos quadros técnicos e administrativos, pois começam a aparecer as escolas técnicas devido a abertura dos portos, o contato com o exterior e, outras culturas que se intensificaram.

Em linhas gerais havia um desinteresse pela educação, e de acordo com Haidar e Tanuri (1998, p.71) "os estudos secundários realizados desordenada e parceladamente achavam-se, quase que exclusivamente, entregues à iniciativa particular".

No período compreendido entre 1860 a 1930 houve poucas mudanças no sistema educacional. Já na década de 1930 conforme Ghiraldelli Junior (2003, p.21), "surgem as primeiras universidades brasileiras e amplas reformas do ensino nos demais níveis, consideradas importantes, embora decorrentes da implementação de um regime autoritário".

Em 25 de janeiro de 1934 segundo Niskier (2011, p. 288) "foi assinado o Decreto $n^{\circ}$ 6.283, que criava a Universidade de São Paulo, tendo por base a Faculdade de Filosofia, Ciências e Letras".

Três anos depois, veio a Constituição de 1937 e com ela uma série de dispositivos de obrigações e do que deveria ser atribuído na prática aos governos federal, estaduais e municipais, em que o ensino pré-vocacional e profissional em matéria de educação era dever do Estado, cumprindo-Ihe dar execução, fundando institutos de ensino profissional, sendo dever das indústrias e dos sindicatos criar na esfera de suas especialidades, escolas de aprendizes, destinadas aos filhos de seus operários ou associados.

De outro lado, a Constituição em 1946 trouxe diversas reformas, que culminou na promulgação em 1961, da Lei de Diretrizes e Bases da Educação Nacional, que de acordo com Haidar e Tanuri (1998, p. 96), "dá-se um importante passo no sentido da unificação do sistema de ensino e da eliminação do dualismo administrativo herdado do Império".

Esta Lei correspondeu a uma das medidas mais importantes feitas pelo Estado em relação à política educacional, e em 1964 houve a ampliação do sistema de ensino, inclusive o superior, juntamente com a criação de agências de apoio à pesquisa e à pósgraduação.

A partir de 1960, o ensino superior brasileiro sofreu uma expansão sem precedentes [...] $\bigcirc$ mercado de trabalho ampliou-se de tal forma que a demanda, principalmente em nível universitário, acompanhou também o ritmo do modelo desenvolvimentistas do presidente Juscelino Kubitschek (NISKIER, 2011, p. 423). 
Segundo Moreira (1998), apesar da nova Constituição em 1988, a educação seguia o texto da LDB de 1961. Em 1996 foi promulgada uma nova LDB que estruturou todo o sistema de ensino brasileiro. Assim, a Lei № 9.394/96 - Diretrizes e Bases para a Educação Brasileira, foi a primeira lei publicada sobre a educação desde 1961, e a estrutura ditada por esta nova lei passou a se preocupar com a educação básica e a educação superior, sendo que a estrutura da educação básica envolve escolas de diferentes graus e diferentes etapas.

Vale destacar que tal condição teve sua amplitude a partir de 2004, com a Portaria no 4.059 que possibilita às Instituições de Ensino Superior a introdução na organização didática pedagógica e curricular dos cursos superiores reconhecidos a oferta de disciplinas integrantes do currículo que também utilizam a modalidade semi-presencial em até $20 \%$ da sua carga total oferecida.

Já na leitura de Niskei (2011, p. 507) "de forma inédita, a Lei n 9.394/96 criou a possibilidade de se diplomar em cursos regulares via ensino a distância (televisão, rádio e Internet, por exemplo)". Isto fez com que a educação a distância passasse a ser reconhecida oficialmente através da implantação desta lei.

Assim e a partir do exposto, fica evidente que a utilização das TICs (Tecnologia da Informação e Comunicação) são de grande relevância, e tornam-se cada vez mais presentes tanto no cenário educacional quanto nas estratégias das organizações que pretendem projetar seus objetivos na modalidade de educação a distância.

\section{Ensino a Distância - EAD}

As operações do Ensino a Distância - EAD são realizadas através de Tecnologias da Informação e Comunicação, e pode ser vista como uma modalidade de educação em que se democratiza o conhecimento.

Segundo o AbraEAD (2008, p. 169) "a EAD é, na prática, a única forma de se democratizar a educação de qualidade em todas as regiões brasileiras, possibilitando o progresso".

Pelo fato de a educação a distância possibilitar mais tempo e espaço de estudo, ela pode ser vista como um ensino democrático, uma vez que não impõe limites geográficos e temporais.

Segundo Silva (2005, p. 63) "se a escola não inclui a Internet na educação das novas gerações, ela está na contramão da história, alheia ao espírito do tempo e, criminosamente, produzindo exclusão social ou exclusão da cibercultura". 
Através da Internet, os acessos à aprendizagem se tornam mais fáceis. Neste sentido, a EAD recentemente surgiu como uma ferramenta de grande importância para a divulgação do conhecimento e da democratização da informação, assim, algumas tecnologias foram agregadas ao ensino, em que o conhecimento pode ser transmitido.

Segundo Bezerra e Carvalho (2011, p. 237) "o avanço tecnológico permitiu que a EAD desse um salto quantitativo com relação à disponibilização de cursos em diferentes níveis de graduação, atendendo a clientelas bastante diversificadas".

Neste sentido o ensino a distância permitiu uma maior interatividade entre as pessoas, e a transmissão do conhecimento se tornou mais fácil, diminuindo a distância, ou seja, as fronteiras e os limites de espaço e tempo entre as pessoas e os lugares mais distantes foram derrubados pelos satélites e computadores, e isto gerou mudanças em todos os setores da sociedade dando um novo significado ao conhecimento.

Segundo Teixeira e Brandão (2003, p. 2) "uma das principais características das tecnologias da informação é a de diminuírem a "distância" entre o ser humano e aquilo que the pode ser extremamente valioso: a informação. Atualmente, um dos principais representantes dessas tecnologias é o computador".

Neste sentido, a Internet abriu espaços na Educação, encurtando distâncias através dos programas a distância aliando tecnologia educacional à Informática e às telecomunicações, possibilitando agilidade e velocidade na comunicação.

Conforme Bezerra e Carvalho apud Souza, Moita e Carvalho (2011) "na Educação a Distância, a ação educativa do professor deve estar centrada na construção de um processo educativo alicerçado na interatividade e na criatividade, na qual deverá provocar discussões, dúvidas e instigar a aprendizagem dos estudantes”.

De outro lado, iniciativas como oferecer cursos ministrados por professores com qualificação são fatores que devem ser incorporados à educação a distância, além do que, esta modalidade demanda algumas condições, em que se tem novos hábitos de estudo, de se aprender, e de lidar com suas dificuldades.

Os professores que atuam em um curso a distância precisam estar atentos a essa nova linguagem e realidade, buscando aplicar as tecnologias de equipamentos de multimídia, intensificando as atividades docentes, na busca da boa interlocução através dos canais de comunicação, e percebendo o desenvolvimento dos alunos com quem mantêm interatividade contínua.

Desta forma, torna-se importante que programas de educação a distância desenvolvam trabalho interativo e esclareçam seus pressupostos pedagógicos, os conhecimentos que serão envolvidos, a estrutura de funcionamento, materiais e suportes 
a serem utilizados e processos de acompanhamento e das formas de avaliação na busca pela aprendizagem perene.

\section{Tecnologia da Informação}

Hoje, a Tecnologia da Informação (TI) é uma das ferramentas mais úteis, e segundo Moura e Albertin (2004, p. 22) "a aplicação e utilização da Tecnologia de Informação parecem cada vez mais uma decisão sem volta, ou seja, nem é possível imaginar o mundo sem o uso de Tl".

Isto porque, a própria velocidade e dinâmica organizacional faz com que se dependa cada vez mais da informação e também da infraestrutura tecnológica para gerenciar as grandes quantidades de dados, isto em função de se trabalhar com sistemas que gerenciem as informações.

Assim, a Tecnologia da Informação é definida como os recursos tecnológicos e computacionais para geração e uso da informação, ou um dispositivo que segundo Cruz (2000, p. 24) "possua capacidade para tratar dados e informações tanto de forma sistêmica como esporádica, que esteja aplicado no produto que esteja aplicado no processo".

Numa gestão de tecnologia de informação segundo Batista (2005) estão inclusos os computadores, os periféricos desses equipamentos que são a parte física, além do software ou programas e seus recursos que correspondem à parte não física.

Por outro lado, há os sistemas de telecomunicações que também integram a Tecnologia da Informação, interagindo de maneira especial com o Sistema de Informação.

O funcionamento de um sistema de telecomunicações, juntamente com seus componentes de hardware e software precisam ser conectados, além dos outros dispositivos de recepção e envio de dados como processadores, canais de comunicação e programas de telecomunicação.

Desta maneira, para Stair (2002) tanto o acesso a dados e informações, como o compartilhamento de recursos, utilizam-se de facilidades que vão desde a simples cópia de dados que se encontram distantes do local de origem/destino, até o complexo relacionamento entre pessoas pelo meio das novas tecnologias, asseguradas e suportadas pelas redes de dados e comunicação.

Nesta percepção e a partir dessa ótica, destaca-se que os sistemas de telecomunicações e seus recursos, assim, como os outros componentes da Tecnologia da 
Informação são fundamentais para o funcionamento dos sistemas computacionais e dos processos de informação no ambiente para a educação como um todo.

Partindo deste cenário, a preocupação dos educadores devem concentra-se agora, na busca de melhor aproveitamento do computador no processo ensino-aprendizagem, e as instituições educacionais devem rever o modelo de ensino para atender às demandas dos estudantes, lembrando-se de que o mercado de trabalho precisa de pessoas informadas e com competências e habilidades em lidar com a tecnologia, o que torna necessário o conhecimento das facilidades na procura constante de informações de maneira flexível e dinâmica.

\section{O papel do professor na educação a distância}

A relação tradicional da sala de aula encontra-se transformada com a educação a distância, que

é uma nova interface entre alunos e professores, mediada pelas tecnologias computacionais, como a Internet, onde os instrutores desempenham o papel de facilitadores, uma vez que os cursos são mais personalizados, cabendo aos alunos cuidar de sua instrução o que reforça a ideia de que os alunos aprenderão por fazer e não por memorização (Maia e Meirelles apud Albertin e Moura, 2004, p. 169).

Então, o papel do professor neste novo modelo de educação é o de facilitador, e os cursos são mais personalizados, uma vez que são os alunos que cuidam de sua própria instrução, cuja aprendizagem ocorre no fazer e não por memorização, o docente aqui é o mediador da aprendizagem do aluno.

Segundo Bezerra e Carvalho apud Souza, Moita e Carvalho (2011, p. 212), "essa modalidade de ensino almeja e concretiza mudanças que vão de uma educação baseada na transmissão da informação, na instrução, para a criação de ambientes de aprendizagem, onde o aluno realiza atividades e constrói o seu conhecimento".

Além disto, os alunos terão mais facilidades com as novas tecnologias, pois, estes são de uma geração habituada a lidar com o computador, que por sua vez, também ajuda o professor a admitir que ele não é mais o detentor de todo o conhecimento, assim, ele passa a fazer parte do processo como um mediador e aprende junto com os alunos.

A figura do professor na EAD pode estar representada pelo especialista que planeja o curso, produz, adequa e garante a qualidade do material didático a ser utilizado e pelo tutor propriamente dito que, de maneira síncrona ou assíncrona, 
presencial ou a distância, garante uma "qualidade comunicacional" para o emprego do referido material e dirige, acompanha e avalia a aprendizagem dos alunos (Oliveira, 2010, p. 20).

De fundamental importância aos cursos a distância, o professor-tutor garante uma integração personalizada e contínua com os alunos através do sistema de comunicação e da tecnologia de informação, tornando assim viável a articulação entre os participantes do processo educativo e da consecução dos objetivos propostos.

A educação escolar atualmente se vê diante da possibilidade de construção de uma nova organização curricular e didáticopedagógica, enriquecida pela diversidade de modelos e conteúdos. Hoje, através da internet, a informação disponibilizada pela tecnologia digital possibilitou o acesso de todos aos fatos, acontecimentos e conteúdos (Tezani, 2011, p. 37).

Em outras palavras, ao lidar com a internet de forma natural, o professor passa a utilizar a potencialidade da rede para orientar os alunos na aquisição de novos conhecimentos, no entanto, também é preciso que a escola esteja atenta ao planejamento de um currículo mais flexível, com a colaboração do corpo docente.

Segundo Bezerra e Carvalho apud Souza, Moita e Carvalho (2011, p. 221), "cabe ao professor pesquisar e propor situações e/ou atividades que levem em consideração os recursos que a tecnologia oferece para ampliar o mundo do aluno, numa perspectiva de reconstrução e de aprendizagem colaborativa".

Nesta nova abordagem de ensino, o docente tem o papel principal, visto que neste cenário ele opina mais sobre o conteúdo abordado, participa da elaboração, dos conteúdos e do acompanhamento das normas que regem disciplinas e convivência, assim, as instituições educacionais, e com isso é parceiro na busca da disseminação e divulgação do conhecimento.

De outro lado, torna-se necessário que o professor acompanhe o desenvolvimento tecnológico, sendo que seu papel deve ser valorizado na sociedade para que ele tenha estímulo de encontrar na tecnologia novas formas de ensino.

Neste sentido, a Internet tem sido uma nova linguagem de comunicação que pressiona a escola a rever seu papel na sociedade, pois, ela possibilita a construção do conhecimento, o que segundo Barbosa (2004, p. 195) "aumenta consideravelmente o potencial dessa tecnologia para uso educacional, uma vez que disponibiliza, com mais facilidade, o acesso às notícias e aos fatos culturais, de tal forma que o aluno possa incrementar seu desenvolvimento intelectual".

De acordo com Tezani (2011, p. 43), "a internet, devido à sua ampla gama de possibilidades de uso, está cada vez mais criativa e interativa. Isso possibilita que o 
trabalho docente faça uso de blogs, sites informativos e interativos, chats, salas de aula virtuais, realidade aumentada etc.".

Em essência, o professor passa a ser um facilitador do conhecimento, como um orientador do processo reconstrutivo do aluno, em que tanto um como o outro são participantes de uma relação comunicativa e interpessoal mais simétrica.

A utilização do computador na construção ativa do conhecimento passa por contemplar as possibilidades de criar e descobrir novas possibilidades para a melhoria da qualidade do processo de ensinar e de aprender, uma vez que o novo, o diferente, estimula o aluno a partilhar a aprendizagem em ambientes que possibilitam vislumbrar descobertas de maneira ativa, engajada, testada. O que muda é a forma de transitar pelo espaço amplo do processo de construir o conhecimento (Faria, 2009, p.21-22).

Entende-se que o papel do professor na educação a distância é o de parceria com seus alunos para que ambos construam o conhecimento em atividades de pesquisa e na busca da inovação pedagógica, oferecendo possibilidades de aprendizagem e estimulando a participação criativa do aluno.

Segundo Bisol apud Valentini e Soares (2010, p.27), “o professor é orientador para indicar os caminhos a serem tomados para chegar ao conhecimento, ao contrário das aulas presenciais nas quais o conhecimento é transmitido diretamente do professor ao aluno".

Afim de que essa nova realidade cresça e se expanda, cabe ao professor buscar por diversos recursos que favoreçam a construção do conhecimento.

\section{Método da pesquisa}

A fundamentação do método deste artigo foi dividida em duas etapas distintas das quais fundamentaram o desenvolvimento deste trabalho. A primeira etapa foi amparada pela revisão bibliográfica da temática relacionada ao assunto "ensino a distância" e "tecnologia da informação", conforme já citado anterior e destacada em item anterior deste artigo.

Já para fundamentar o método empírico para este estudo utilizou-se da pesquisa na forma qualitativa. Na concepção de Miguel et al. (2010), na abordagem qualitativa, a realidade subjetiva dos indivíduos envolvidos na pesquisa é considerada relevante e assim contribui para o desenvolvimento da pesquisa e do entendimento do cenário ao qual se queira estudar.

Contextualizando o método qualitativo, Triviños (2006), aponta que a abordagem qualitativa considera tanto o ambiente interno quanto o ambiente externo do estudo, e 
assim, exerce influência sobre as pessoas, as quais realizam suas ações em função do seu ponto de vista sobre o ambiente em que estão inseridas. Ainda assim, Chizotti (2001), compartilha da visão que tal método permite por meio da análise de como as pessoas interpretam o ambiente, pode-se ter a melhor explicação de como elas desenvolvem suas atividades.

Desta forma, para dar embasamento sustentável a esta pesquisa, coletaram-se os dados da amostra por intermédio de questionário semi-estruturado utilizando escala de Likert e quando necessário detalhando as respostas para apuração detalhada da percepção do respondente, conforme apresentado no final deste artigo.

Para obtenção dos dados da amostra foram entrevistados 50 (cinquenta) docentes de um curso de tecnologia em uma Instituição de Ensino Superior, localizada na grande São Paulo cujo universo da amostra atingiu 100\% dos docentes envolvidos no curso avaliado neste estudo. Os questionários foram enviados aos docentes através do correio eletrônico pessoal e tabulado na forma e ordem de recebimento das respostas. As análises das respostas foram efetuadas a partir da tabulação do arquivo eletrônico, e posteriormente, foram estabelecidas categorias de importância, buscando assim refletir sobre os resultados obtidos. Para análise da percepção das respostas, buscou utilizar a análise de conteúdo, que na percepção de Bardin (2009), detecta nas características de uma resposta, seu contexto e quais condições induziram essa mensagem.

Por fim, buscou-se correlacionar a hipótese dessa pesquisa, com os resultados alcançados e discutidos nos itens conforme abaixo discriminados.

\section{Análise de dados}

Este item apresenta as respostas da pesquisa realizada com cinquenta professores que ministram aulas no curso superior de tecnologia a distância.

Estes docentes exercem suas atividades em uma Universidade privada que oferece o curso superior em tecnologia àqueles alunos que desejam fazê-lo pelo sistema virtual ou Internet.

A iniciativa privada, por sua vez, tendo explorado todos os caminhos da educação superior presencial (os cursos de fácil oferta bacharelados, licenciaturas e tecnológicos) e tendo já experimentado, ali, os limites da demanda, bateu às portas do MEC, solicitando credenciamento para atuar com educação a distância (Giolo, 2008, p. 1224).

Cabe aqui esclarecer que o recurso computacional usado no curso é a Internet, onde o aluno acessa o site da Universidade por meio de seu registro acadêmico e de uma 
senha, faz acesso ao conteúdo (aulas, fóruns, chat, atividades e material didático), para acompanhamento e desenvolvimento das aulas.

Dentre as questões feitas aos professores entrevistados (conforme questionário da pesquisa de campo), para efeito de tabulação, as respostas foram divididas em Parte $A$ (Perfil Profissional) e Parte B (Atividades de Ensino e Aprendizagem). Ao analisar as respostas relacionadas a Parte $A$ do questionário, fica evidente a grande experiência do corpo docente, visto que $84 \%$ ou seja 40 professores responderam ter acima de 7 anos de experiência no ensino distancia, tanto na IES quanto fora desta. Outro fator relevante que contribui para a formação do discente, foi o grande número de professores titulados na área da disciplina ministrada, demonstrando neste item plena aderência ao conteúdo ministrado. Dos 50 professores entrevistados, quase a sua totalidade tem formação em programa de stricto sensu, cerca de $90 \%$, ou seja 44 dos 50 professores avaliados.

Já em relação ao número de alunos por disciplina/docente, índice não foi alto, apresentando uma relação de 60 alunos por disciplina/docente. Isso posto, fica evidente que a IES ao qual aplicou-se a pesquisa para o curso avaliado, tem a preocupação na busca pelo equilíbrio aluno x professor e a qualificação x formação profissional exigida.

Neste contexto, tal preocupação avaliada neste item, vem ao encontro na condição de padrões de qualidade exigida pelo Ministério da Educação nos indicadores de qualidade docente e de formação acadêmica.

Em seguida, na Parte B (que trata as questões relacionadas as variáveis de ensino e aprendizagem) perguntou-se de que maneira focada questões que estavam relacionadas aos itens: ensino e aprendizagem; atividades on line, comunicação na plataforma AVA, construção do conhecimento; utilização de recursos computacionais e dimensão da disciplina em relação ao Projeto Pedagógico do Curso.

O desdobramento das respostas obtidas da Parte B deste questionário apontam para respostas que coadunam a seguinte percepção dos docentes, conforme segue:

\section{Atividades On Line}

Fica evidente pelos professores entrevistados, que aqui, cada um utiliza tanto a sua experiência pessoal quanto a bagagem profissional estimulando as discussões e reflexões sobre o tema da sua disciplina. Fica evidente na "redação" de um dos professores entrevistados, por exemplo que, a experiência do docente na condução das discussões propostas nas atividades on line, fazem toda a diferença, pois quando bem direcionada e conduzida de forma a relacionar o saber do "acadêmico" e o fazer 
"profissional", o ganho nas aulas é rico e notório. Isso fica evidente na resposta do docente, aqui identificado como D8 “[...] A atividade na plataforma estimula o grupo a pensar de forma crítica, apesar de nem sempre ser possível dar a devida profundidade no tema proposto[...]".

Porém apesar de todos os docentes destacaram a importância de atividades profissionais e o aprofundamento das discussões na plataforma, não se pode perceber de forma clara, quando do desdobramento das questões, a uniformidade na condução de um cronograma mínimo de atividade. Isso foi percebido de forma objetiva, visto que dos 50 professores, 32 buscaram trabalhar com apenas uma atividade por aula, já 18 desses, abriram atividades em momentos distintos. Um ponto relevante a ser destacado na pesquisa é o fato de que a construção do conhecimento neste estudo em particular estar muito relacionado as questões empíricas e vivenciadas pelos acadêmicos, acredita-se que tal fato esteja diretamente relacionado a falta de formação deste docente na área pedagógica/licenciatura, apesar desse não ser condição essencial para o perfil do público avaliado.

\section{Comunicação na Plataforma}

Já quando o indicador avaliado se relacionava com Comunicação na Plataforma AVA, fica evidente a importância desta variável, bem como a forma peculiar e individual de cada indivíduo trabalhar. (Cavallari, 2011) destaca nos seus estudos a importância do processo de interação/interatividade entre os alunos e professores nas diferentes formas de comunicação e troca de informação. Ainda segundo a autora a participação ativa de professor e aluno é trabalho árduo, que busca a interatividade entre as diversas mídias e ferramentas tecnológicas e os diversos atores envolvidos.

Diante da clareza, para o item avaliado, fica evidente que o fato de existir um ordenamento lógico e sistêmico dos docentes, gera condição de vantagem competitiva ao estudo realizado.

Porém vale destacar, que ainda alguns respondentes apontam ser importante institucionalizar a forma e os canais de comunicação dentro da plataforma de estudo, separando por exemplo, fóruns por temáticas especificas (p.ex. "fórum de dúvidas da disciplina X",), com informações do curso e ou da disciplina.

$\mathrm{Na}$ mesma esteira os dados da pesquisa apontam que $80 \%$ dos professores interagem pela Internet, e os outros $20 \%$ apontam os chats como um meio de interação com o aluno. 
Neste contexto, corrobora-se com a percepção de (GIOLO, 2008, p. 1228), ao qual menciona ser bom o professor que vive profundamente uma experiência cultural e se apropria, sistematicamente, dela e dos meios necessários para proporcionar a outrem a mesma experiência e a mesma apropriação. Nesse conjunto de atividades, o ambiente (o lugar onde as coisas acontecem) e a natureza das relações que ali se constroem não são elementos neutros; são dimensões integrantes e constitutivas do processo.

\section{Recursos computacionais e material didático}

Quando a indagação foi a utilização dos recursos computacionais conforme relacionado com a questão 8 do questionário, aqui não houveram grandes diferenças nas respostas colhidas. Ficou evidente que grande parte dos docentes entrevistados detém conhecimento no ambiente de trabalho e nos recursos computacionais fornecidos pela Universidade estudada. Porém o destaque, neste ponto é que, nem todos os docentes utilizam todos os recursos disponíveis, pois muitos desse complementam as suas experiências em outras plataformas de estudo que não a da organização. Isso traz um ponto desfavorável a organização, visto que a fatal de registro no ambiente virtual de aprendizagem da Universidade por alguns docentes faz com que muito do discutido se perca fora o ambiente da instituição, não sendo possível em momento futuro o mapeamento para decisões futuras.

\section{Dimensão da disciplina em relação ao Projeto Pedagógico do Curso}

$\mathrm{Na}$ pesquisa em si, este foi um dos tópicos que merecer destaque e detalhamento visto a concordância nas respostas indicadas pelo corpo docente. Ao questionar a relação entre a compreensão do conteúdo da disciplina em relação ao projeto pedagógico do curso, foi unânime a compreensão que o entendimento por parte dos docentes das relações entre o projeto pedagógico e o perfil do egresso é fator de impacto no sucesso na condução do estudo realizado. Somado a isso, acredita-se que pelos dados coletados e pela experiência do autor, que as recentes visitas de avaliação do Ministério da Educação para o curso avaliado, traga aos docentes avaliados experiência e maturidade acadêmica para tal.

\section{Dimensão tempo de estudo}


Neste quesito todos os professores responderam que após as aulas virtuais os alunos têm um tempo para assimilar o que foi aprendido, eles podem rever as aulas, e as dúvidas podem ser esclarecidas através de chats (bate papo num fórum virtual). Após esse procedimento são colocadas em sua plataforma atividades corrigidas e comentadas.

Quando o material didático utilizado na EAD é bem elaborado, de acordo com as características que Ihe são próprias, ele possibilita ao aluno uma avaliação constante de seu progresso e de suas dificuldades, dando-Ihe ensejo de continuar e/ou indicativos da necessidade de buscar orientação complementar, seja do sistema de tutoria ou de outro sistema de apoio que esteja disponível (Azzi 2005, p. 187).

E, por fim, a pesquisa de uma forma geral revela sobre o papel do professor no curso a distância que o professor tem como papel ajudar o aluno a aprender, criar condições para que ele adquira informações, e organizar estratégias para que este conheça e construa seu próprio conhecimento. Todavia $20 \%$ as respostas informam que o professor tem o papel de alguém que gera dinâmica entre os participantes, e o restante disse que e o de interagir com o aluno, atuar como moderador as discussões.

Vale salientar que mediante a implementação da prática educativa nessa modalidade com a imersão das novas tecnologias, também é reforçado o papel do professor como aprendente. Isto se dá porque, na medida em que ensina, está aprendendo continuamente sobre si próprio, sobre $o$ aluno e sobre o mundo que o cerca exigindo, principalmente, outras habilidades como, por exemplo, o manuseio e utilização das novas ferramentas tecnológicas como suporte para o trabalho pedagógico (Araujo e Carvalho apud Souza, 2011, p. 188).

Tendo em vista tais informações, e conforme discutido nos itens acima relacionados, podemos notar que na EAD, o grande desafio está em manter um bom relacionamento com todos os que participam neste tipo de processo educacional, além disto, a comunicação deve ser dinâmica com os educandos, e a constante interação é fundamental para o acompanhamento deles.

Assim, os professores são o elo de conexão entre os discentes, porque eles incentivam relacionamentos entre os alunos na realização de atividades que exigem pesquisas por meio eletrônico nas trocas individuais de informações.

\section{Conclusão}

A tecnologia da informação na educação através do ensino a distância, em curso técnico superior mostra um grande desafio, em que combina o técnico com o pedagógico, 
cabendo ao mediador (professor) orientar, e ao aluno assimilar a construção de novos conhecimentos através da atividade computacional.

O professor que agora é chamado de mediador e deve criar condições para que o aluno construa seus conhecimentos, assim, o sistema fragmentado de ensino passa por uma abordagem mais integradora.

Portanto, através da tecnologia de informação e comunicação no ensino a distância em curso técnico superior, a preparação deste mediador (professor) é fundamental, uma vez que ele incorpora aspectos da construção do conhecimento pelo aluno.

Diante do exposto, este artigo atingiu seus objetivos propostos, bem como respondeu ao problema levantado através de uma pesquisa de campo, em que os pesquisados revelam que o papel do professor no curso a distância é o de ajudar o aluno a aprender, criar condições para que ele adquira informações, e organizar estratégias para que este conheça e construa seu próprio conhecimento.

Em outras palavras, a modalidade a distância determina que os professores tenham mais conhecimento e habilidades, ou seja, saberes que vão além do processo didático, daí a necessidade em utilizar recursos tecnológicos que permitem um aperfeiçoamento das relações no ensino a distância, e são como interfaces mediadoras na relação professor/estudante/conhecimento.

Cabe aqui esclarecer que a presente pesquisa encontra-se limitada aos professores de uma única Instituição privada de ensino superior, assim, sugere-se como trabalho futuro que este estudo possa ser realizado com uma quantidade maior de pesquisados, e que envolva outras instituições, públicas e/ou privadas, e que se faça um trabalho mais aprofundado para averiguar variáveis distintas do que as somente estudadas neste estudo. 


\section{Referências}

ABRAEAD. Anuário Brasileiro Estatístico de Educação Aberta e a Distância, 2008. São Paulo: Instituto Monitor, 2008.

Araujo, Maria Dalva de Oliveira; Carvalho, Ana Beatriz Gomes. 0 sociointeracionismo no contexto da EAD: a experiência da UFRN. In: Sousa, Robson Pequeno de et al. (org.)Tecnologias digitais na educação. Campina Grande: EDUEPB, 2011.

Avancini, Marta; Conte, Fabiano; Gouveia, Flávia. Pierre Lévy: Um dos mais conhecidos pensadores da cibercultura, o filósofo Pierre Lévy falou sobre conhecimento e interação com as tecnologia de informação e comunicação, em entrevista coletiva no Auditório da Coordenadoria de Tecnologia da Informação da USP. ComCiência, Campinas, $\quad$ n. 131, $2011 \quad$. disponível em <http://comciencia.scielo.br/scielo.php?script=sci_arttext\&pid=S151976542011000700013\&lng=en\&nrm=iso >. Accessado em 17/04/2019.

Azzi, Sandra. Avaliação de desempenho do aluno na EAD. In: Secretaria de Educação a Distância. Integração das tecnologias na educação. Brasília: Ministério da Educação, Seed, 2005.

Barbosa, Jânia do Valle. Do giz ao mouse - a informática no processo ensinoaprendizagem. In: Colombo, Sonia Simões. Gestão educacional: uma nova visão. Porto Alegre: Artmed, 2004.

Bardin, L. Análise de Conteúdo. Lisboa, Portugal; Edições 70, LDA, 2009.

Batista, Emerson de Oliveira. Sistemas de informação: 0 uso consciente da tecnologia para o gerenciamento. São Paulo: Saraiva, 2005.

Bezerra, Mayam de Andrade; Carvalho, Ana Beatriz Gomes. Tutoria: concepções e práticas na educação a distância. In: SOUSA, Robson Pequeno de; Moita, Filomena da M. C da S. C; Carvalho, Ana Beatriz Gomes (org.) Tecnologias digitais na educação. Campina Grande: EDUEPB, 2011.

Bisol, Claudia Alquati. Ciberespaço: terceiro elemento na relação ensinante/aprendente.In: Valentini, Carla Beatris; Soares, Eliana Maria do Sacramento (org.). Aprendizagem em ambientes virtuais [recurso eletrônico]: compartilhando ideias e construindo cenários. Caxias do Sul, RS: Educs, 2010.

Brasil - Ministério Da Educação E Cultura. Lei no 4.024, de 20 de dezembro de 1961. Fixa as Diretrizes e Bases da Educação Nacional. MEC/CFE. $3^{a}$ Ed. Rio de Janeiro, marços de 1962.

Brasil - Ministério da Educação e Do Desporto Cultura. Lei no 9.394/96 de 20/12/1996. Estabelece ass Diretrizes e Bases da Educação Nacional. Imprensa Nacional, Brasília, Diário Oficial da União, Seção I, 23/12/1996. 
Cavallari, Mônica Regina. "Tecnologias, educação e a interação no ambiente virtual.," Anais do IV Encontro de Pesquisa Discente do Programa de Pós Graduação em Educação da UNINOVE, , acessado em http://www. http://www.uninove.br/marketing/viii coloquio/pdfs/completos/Cavallari Monica Regina.pd f, acessado em 30/04/2019.

Cervo, Arnaldo Luiz et al. Metodologia científica. São Paulo: Pearson Prentice Hall, 2010.

Chizzotti, A. 2001. Metodologia do ensino superior: o ensino com pesquisa. In: S.

Castanho e M. E. Castanho (orgs.), Temas e textos em Metodologia do Ensino Superior. São Paulo, Papirus.

Cruz, Tadeu. Sistemas de Informações Gerenciais - Tecnologia da Informação e a Empresa do Século XXI. São Paulo: Atlas, 2000.

Faria, Elísio Vieira de. A tecnologia da informação e da comunicação como ferramenta para a construção e democratização do conhecimento. In: Scientia FAER, Olímpia - SP, Ano 1, Volume 1, 2ํㅗㄴ Semestre. 2009.

Freitag, Barbara. Escola, estado e sociedade. São Paulo: Moraes, 1986.

Gadotti, Moacir. Concepção dialética da educação. São Paulo: Cortez, 2010

Ghiraldelli Junior, P. História da Educação. São Paulo: Cortez, 2003.

Gil, Antônio Carlos. Como elaborar projetos de pesquisa. São Paulo: Atlas, 2002.

Giolo, Jaime. A educação a distância e a formação de professores. In: Educ. Soc., Campinas, vol. 29, n. 105, p. 1211-1234, set./dez. 2008

Haidar, Maria de Lourdes Mariotto; Tanuri, Leonor Maria. A Educação Básica no Brasil: dos primórdios até a primeira lei de diretrizes e bases. In. Estrutura e Funcionamento da Educação Básica. São Paulo: Pioneira, 1998.

Maia, Marta de Campos; Meirelles, Fernando de Souza. As tecnologias de informação e comunicação aplicadas na educação a distância no ensino superior no Brasil. In: Albertin, Alberto Luiz; Moura, Rosa Maria de. Tecnologia de informação. São Paulo: Atlas. 2004.

Moreira, Roberto. A estrutura didática da educação básica. In. Estrutura e Funcionamento da Educação Básica. São Paulo: Pioneira, 1998.

Moura, Rosa Maria de; Albertin, Alberto Luis. Benefícios da Tecnologia de Informação no desempenho organizacional. Tecnologia de Informação. São Paulo: Atlas, 2004.

Neves, Carmen Moreira de Castro. A educação a distância e a formação de professores. In: Secretaria de educação a distância. Integração das tecnologias na educação. Brasília: Ministério da Educação, Seed, 2005 
Niskier, Arnaldo. História de educação brasileira: de José de Anchieta aos dias de hoje, 1500-2010. São Paulo: Editora Europa, 2011.

Oliveira, Eloiza da Silva Gomes de. Ação docente na educação a distância: as competências do "professor invisível". Revista Tecnologia Educacional. Ano 39 - no 190 - julho/setembro de 2010.

Rezende, Denis Alcides. Tecnologia de Informação aplicada a sistemas de informação empresariais: o papel estratégico da informação e dos sistemas de informação nas organizações. São Paulo: Atlas, 2003.

Silva, Marcos. Internet na escola e inclusão. In: Secretaria de educação a distância. Integração das tecnologias na educação. Brasília: Ministério da Educação, Seed, 2005.

Stair, R. M. Princípios de sistemas de informação: uma abordagem gerencial. Rio de Janeiro: LTC, 2002.

Teixeira, Adriano Canabarro; Brandão, Edemilson Jorge Ramos Internet $\boldsymbol{e}$ democratização do conhecimento: repensando o processo de exclusão social. CINTED-UFRGS na Educação V. 1 № 1, Fevereiro, 2003 Disponível em:< http://seer.ufrgs.br/renote/article/viewFile/13635/7711>. Acesso em 27 Abr. 2019.

Tezani, Thaís Cristina Rodrigues. A educação escolar no contexto das tecnologias da informação e da comunicação: desafios e possibilidades para a prática pedagógica curricular. In: revistafaac, Bauru, v. 1, n. 1, p. 35-45, abr./set. 2011.

Triviños, A. N. S. Introdução à pesquisa em ciências sociais. São Paulo: Atlas, 2006. 